\title{
The Forgotten Evaluation: Taking Competence Seriously
}

Seth E. Tabb, MD

UCLA Neuropsychiatric Institute

Scott A. West, MD

University of Cincinnati, Cincinnati, Ohio

Follow this and additional works at: https://jdc.jefferson.edu/jeffjpsychiatry

Part of the Psychiatry Commons

Let us know how access to this document benefits you

\section{Recommended Citation}

Tabb, MD, Seth E. and West, MD, Scott A. (1995) "The Forgotten Evaluation: Taking Competence Seriously," Jefferson Journal of Psychiatry. Vol. 12 : Iss. 2 , Article 9.

DOI: https://doi.org/10.29046/JJP.012.2.005

Available at: https://jdc.jefferson.edu/jeffjpsychiatry/vol12/iss2/9

This Article is brought to you for free and open access by the Jefferson Digital Commons. The Jefferson Digital Commons is a service of Thomas Jefferson University's Center for Teaching and Learning (CTL). The Commons is a showcase for Jefferson books and journals, peer-reviewed scholarly publications, unique historical collections from the University archives, and teaching tools. The Jefferson Digital Commons allows researchers and interested readers anywhere in the world to learn about and keep up to date with Jefferson scholarship. This article has been accepted for inclusion in Jefferson Journal of Psychiatry by an authorized administrator of the Jefferson Digital Commons. For more information, please contact: JeffersonDigitalCommons@jefferson.edu. 


\title{
The Forgotten Evaluation: Taking Competence Seriously
}

\author{
Seth E. Tabb, M.D. \\ Scott A. West, M.D.
}

\begin{abstract}
The medical literature devotes little attention to the application of competency to the general medical patient. Commonly, the only cases recognized as necessitating a competency evaluation are overtly psychotic patients, patients requiring written informed consent, and those patients who refuse treatments strongly recommended by their physician. Clarifying terminology and redefining competency provides a practical screening method for assessing competency in all patients. When physicians neglect the evaluation of competency, patient autonomy is compromised. Not only are all physicians capable of performing a competency evaluation, they are ethically and professionally required to do so.
\end{abstract}

The increasing interest in the issue of competency is as evident in clinical settings as it is in the medical literature (1). However, this interest in competency issues has been limited to a select population. This population predominantly consists of patients with overt psychiatric symptoms, patients undergoing procedures that require written informed consent, and those patients who refuse treatment strongly recommended by their physician. There has been little attention in the literature devoted to the application of competency to the general medical patient.

Informed consent preserves patient autonomy and is the most visible reminder of the need to evaluate competency, since the patient cannot give informed consent if he or she is not competent. Unfortunately, the question of competency seldom arises unless the consent must be documented or the patient disagrees with the physician's recommendations. Physicians should be aware of the importance of competency issues with all patients if informed consent is to be valid. But before we can discuss the practical applications of these issues, terminology and definitions must be specified since the terms surrounding these issues are often used in ambiguous ways.

In reviewing the literature on competency issues, a great deal of confusion exists about the medical versus legal definitions of competency, who is capable or authorized to assess it, and the role of the physician in this evaluation process (2-11).

Seth E. Tabb, M.D. is Chief Fellow in the Division of Child and Adolescent Psychiatry at the UCLA Neuropsychiatric Institute. Scott West, M.D. is a Research Fellow in the Biological Psychiatry Program at the University of Cincinnati. 
Watson (4) accurately simplifies this matter by pointing out that "the words 'competent' and 'insane' both (are) legal words that can only be appropriately and accurately used after a fact-finding process." However, the medical profession has adopted the term 'competence' and determines the 'competency' of their patients daily, without judicial involvement (3). But these competency evaluations have no binding legal authority. As Schreiber et al. (11) explain, "the court is not bound to find competency or incompetency in accordance with the hospital report, although it almost invariably does so."

Although always applied to a specific medical question or issue, competency remains an evolving concept. This is supported by the fact that the law has not established universal requirements for its determination (1). Competency, as described by Kaplan et al. (6), "represent(s) an attempt to balance issues of the individual's ability to make decisions with the individual's autonomy and civil liberties. Current tests of competency attempt to address these issues." From this assessment, competency should be defined by the following four factors: (1) the ability to communicate and understand information, (2) sufficient capacity of medical information and rational manipulation of this data, (3) the absence of any interfering known pathologic or social condition, and (4) the possession of a set of internally consistent values and goals $(12,13)$. All of the above criteria must be met for a patient to be competent. These criteria are somewhat ambiguous and abstract (leaving much leeway for professional interpretation), but with further investigation these terms will become more quantifiable. In the application of this definition, two other terms are utilized and need to be clarified. "Capacity" is a person's ability to absorb and retain information. "Rationality" is having or exercising the ability to reason.

The most controversial of these criteria is the possession of a set of internally consistent values and goals. This criterion must be carefully evaluated because of the potential dangers of such an evaluation. It would be tragic if a patient was declared incompetant because their competence was questioned due to a valid but unique or unpopular set of values. Within these unique values, as long as the patient is internally consistent in reason, they must be deemed rational (but not necessarily competent). For example, consider the following case:

An elderly widow is advised to undergo an elective cholecystectomy but declines and states that if she were hospitalized, "I would miss my pet poodle too much." Upon further evaluation, she explains that her relationship with her dog is the only meaningful connection left in her life, and that separation from the dog for any length of time is unbearable. She recognizes that other people would view her decision as "strange" or "ridiculous," but remains steadfast in her refusal of the procedure. She regards any negotiated visits with the poodle while hospitalized as "unacceptable." No other unusual value system is discovered during the evaluation and she has an unremarkable mental status examination and past history. 
Is this an incompetent patient or is this a case of differing values? The latter view must be supported because: (1) no pathologic or social condition is found to influence her decision, (2) she is capable of manipulating relevant medical information (i.e. evaluates risk/benefit ratio of procedure), and (3) the consistency of her value system is rational.

Drane (12) defines a "sliding scale" model for determining competence levels that account for the variety of clinical settings, patients' cognitive and communicative abilities, severity of illness and probable treatment outcomes in assigning a level of competency to a patient who consents to a specific medical intervention. This spectrum of competency ranges from "no impairment" to "global incompetence." Because a patient's competency may fluctuate, continued re-evaluations are mandated (14).

It must be emphasized that competency is applied to a specific decision regarding a specific medical therapy. Consider the following illustrative case:

A pathologically paranoid patient sustains an injury in an automobile accident. While obtaining informed consent, the patient reveals a delusion about his neighbor, Abraham Lincoln, blaming him for causing the accident. When asked to consent to medical treatment the patient states, "Do anything you want to do to me. Just hide me from Abe."

If the decision to agree to medical treatment is not influenced by the delusion, then valid informed consent can be obtained. However, if the patient incorporates the treatment or its potential outcome into his delusion (e.g., the patient can escape persecution from his neighbor by remaining in the hospital), legal informed consent is not valid because the prerequisite of competency has not been met, even though the decision may appear to be the right one or best one.

Although psychiatrists are often consulted to perform evaluations on patients presumed to be incompetent, it is within the role of every physician to assess competency. As Golinger and Fedoroff (15) point out, "Most evaluations, such as those to determine whether a patient is competent to sign a consent form, understand the risk of taking a specific medication, or choose between various treatment alternatives, are made by a physician without psychiatric consultation." For example, the family physician may be in an excellent position to assess competency due to a longitudinal relationship with the patient, which enables him or her to detect subtle changes in the patient, which may require closer evaluation (16).

Competency evaluation, as a prerequisite to informed consent, is not necessary when a medical emergency exists or the doctor exercises "therapeutic privilege" (e.g., withholding information or knowledge regarding treatment) (1). Although the ethics involved in exercising "therapeutic privilege" are beyond the scope of this paper, it should be noted that competency is not a factor in its application. In addition to the above, minors are deemed legally incompetent to make most medical decisions. Consent, assent, and the absence of dissent from minors are also beyond the scope of this discussion. 
Rather than consciously incorporate a competency assessment into their history, physical examination and consent process, most physicians simply assume competency of their patients. Unfortunately, this is accepted practice. We would like to emphasize the lack of literature pertaining to the assessment of competency in all but the most overt cases of incompetence. The literature states that all adults are presumed competent (16) unless substantive questions arise about the patient's competence $(17,20)$ or the patient refuses the suggested medical treatment (12). But assumption, and not a conscious assessment of competency, carries ethical ramifications.

By assuming a patient is competent, the physician believes he or she is respecting the patient's communicated freedom of choice, but to respect what may be an expression of freedom only in appearance would be a violation of a basic principle of ethical medicine: that of respecting the autonomy of patients (18). This usually falls under the guise of paternalism. Although there is a long history of paternalism in medicine, it is now generally recognized that this approach has limited application in current patient care practices. As Marzuk (19) illustrates, current medical care demands that physicians be sensitive to the doctor-patient relationship and the dynamics involved in the patient's medical decision-making process, thus necessitating paternalistic actions under special circumstances. However, there are several relatively common situations where paternalism remains widely unrecognized.

If a patient demonstrates even the slightest sign of incompetence but agrees to the suggested therapy, it is our responsibility as physicians to appreciate the potential impairment and formally evaluate the patient's competence. Failure to recognize the possibility of incompetence or assuming competence for the gain of uncontested acceptance of a prescribed medical regime are the disguised acts of paternalism that we cannot accept. Case 3 illustrates this point.

An elderly gentleman with recent manifestations of Alzheimer's Disease is evaluated in the emergency room. The patient complains of a "sore foot" which is diagnosed as gaseous gangrene. After consultation an amputation is recommended, to which the patient readily agrees.

Typically, the physician feels no need to assess competency while dispensing routine medical care unless the capacity for rational decision-making is grossly impaired. (This was reflected in the consults for competency evaluation by Golinger and Fedoroff (15) who found 78.5 percent of these patients to have organic mental disorder). But when the patient refuses the suggested medical treatment the physician commonly responds by requesting a formal consult for competency evaluation. It is clear that protecting the incompetent from the harm of a poor decision is an act of benevolence, but we must also guard against "reactive paternalism" on the part of the physician when patients refuse a suggested treatment (9).

As experts in medicine, physicians believe that their suggestions are in the best interest of the patient. But we must realize that what is in the best interest of the patient is not necessarily a medical issue. "Patients must be permitted to determine their own fate, and a decision cannot be set aside simply because it differs from what 
other persons think is indicated" (12). Because physicians are intensely trained in the treatment of disease, it is easy to isolate medical interests from the social context in which they arise. We must avoid this mistake.

It is unrealistic to think that a significant number of treatment decisions would be affected if physicians formally challenged every patient's competency; yet because of the profound consequences for those patients whose autonomy is unjustifiably violated, a systematic, conscious screening method of competency evaluation is mandated. The cost/benefit ratio is reduced when physicians become knowledgeable of current competency standards and are aware of the ethical implications of their actions. As physicians become more aware of the need for assessing competency, our actions will be less likely to encroach on the autonomy of our patients. Not only are all physicians capable of performing a competency evaluation, they are ethically and professionally required to do so. Patients must be permitted to determine their own fate, and as physicians, we must protect this right. This can only be accomplished when we take competence seriously.

\section{ACKNOWLEDGMENTS}

The authors wish to thank Ray Moseley, Ph.D. for his assistance in reviewing and editing, Michael Ware, MD for reviewing, and Ralph Grams, MD.

\section{REFERENCES}

1. Mahler J, Pery S: Assessing competency in the physically ill; guidelines for psychiatric consultants. Hospital and Community Psychiatry. 1988; 39:856-861

2. Owens H, Rosner R, Harmon R: The judges view of competency evaluations II. Bull Am Acad Psychiatry Law. 1987; 15:381-389

3. Haddad A: Determining competency. Journal of Gerontological Nursing. 1988; 14:19-22

4. Watson A: Comment. Am J Psychiatry. 1984; 141:58-60

5. Miller R: The treating psychiatrist as forensic evaluator. J Forensic Sciences. 1984; 29:825-830

6. Kaplan K, Strang J, Ahmed I: Dementia, mental retardation, and competency to make decisions. General Hosp Psychiatry. 1988; 10:385-388

7. Radelet M, Barnard G: Ethics and the psychiatric determination of competency to be executed. Bull Am Acad Psychiatry Law. 1986; 14:37-51

8. Reich J, Tookey L: Disagreements between court and psychiatrist on competency to stand trial. J Clinical Psychiatry. 1986; 47:29-30

9. Drob S, Berger R, Weinstein H: Competency to stand trial: a conceptual model for its proper assessment. Bull Am Acad Psy Law. 1987; 15:85-94

10. Owens H, Rosner R, Harmon R: The judges view competency evaluations. Bull Am Acad Psychiatry Law. 1985; 13:389-397

11. Schreiber J, Roesch R, Golding S: An evaluation of procedures for assessing competency to stand trial. Bull Am Acad Psychiatry Law. 1987; 15:187-203

12. Drane J: The many faces of competency. Hastings Center Report. 1985; 15:17-21

13. Hundert E: A model for ethical problem solving in medicine, with practical applications. Am J Psychiatry. 1987; 144:839-846 
14. Schwartz H, Blank K: Shifting competency during hospitalization: a model for informed consent decisions. Hospital Community Psychiatry. 1986; 37:1256-1260

15. Golinger R, Fedoroff J: Characteristics of patients referred to psychiatrists for competency evaluations. Psychosomatics. 1989; 30:296-299

16. Farnsworth M: Evaluation of mental competence. J Am Acad Family Physicians. 1989; 39:182-190

17. Applebaum P, Grisso T: Assessing patients' capacities to consent to treatment. NEJM. 1988; 319:1635-1638

18. Drane J: Competency to give informed consent; a model for making clinical assessments. JAMA. 1984; 252:925-927

19. Marzuk P: The right kind of paternalism. NEJM. 1985; 313:1474-1476

20. Sullivan M, Youngner S: Depression, competence, and the right to refuse lifesaving medical treatment. Am J Psychiatry. 1994; 151:7 